\title{
Activity and stability of immobilized lipases in lipase-catalyzed modification of peanut oil
}

Mohamed M. SOUMANOU ${ }^{1}$

Aleodjrodo P. EDORH ${ }^{2}$

UWe T. BORNSCHEUER ${ }^{3}$

${ }^{1}$ Research Laboratory for Applied Chemistry and Biology (LARECBA), Abomey-Calavi Polytechnic

School, Abomey-Calavi University,

01 BP 2009, Cotonou, Benin

<msoumanoufr@yahoo.fr>

2 Faculty of Sciences and Technics,

Department of Biochemistry and Cellular

Biology,

BP 526, Cotonou, Benin

${ }^{3}$ Institute of Chemistry and Biochemistry,

Department of Technical Chemistry and

Biotechnology, University Greifswald,

Soldmannstr,

16, D-17487 Greifswald, Germany

Article received on 14/09/2004

accepted on 17/1/2005

\begin{abstract}
Fatty acid release during lipolysis of peanut oil using microbial free and immobilized lipases in aqueous media was developed. Immobilized lipase from Rhizomucor miehei (RML) gave the best result from its ability to clive different fatty acids from peanut oil in such media. In organic solvent, interesterification of peanut oil with tricaprylin using immobilized lipases from RML, Chromobacterium viscosum (CVL) and Candida rugosa (CRL) was performed. The best substrate molar ratio of tricaprylin to peanut oil found was in the range 0.7 to 0.8 . Using substrate molar ratio 0.7 , high amount of structured triglyceride ST (about 35\% MLM, 44\% LML triglyceride fractions) was obtained with lipase from RML in $n$-hexane. The results found in solvent free system were in some cases quite similar to that obtained in organic solvent. In nine successive batch interesterification in solvent free medium using immobilized RML and CRL, no significant loss of amount of both produced triacylglycerol fractions until batch 7 was observed with RML.
\end{abstract}

Key words: interesterification reaction, peanut oil, microbial lipases, immobilization, structured triacylglycerols, stability

Lipid modification strategies for industry include processes such as fractionation, hydrogenation and interesterification. While each of the two first processes has specific uses and advantages, interesterification reaction offers the greatest potential application [1]. It includes three approaches: acidolysis, alcoholysis and transesterification. Chemically, it can be induced by the use of alkali catalysts in a reaction which lacks specificity and offers little or no control over the positional distribution of fatty acids in the final product [1, 2].

To overcome such difficulties, enzymatic approach is used. Applied biocatalysts are microbial lipases and are based mainly on their specificity. They are divided in two main groups: random lipases, which cleave fatty acids at all position on the glycerol molecule (e.g. lipases from Candida antarctica, Candida rugosa, Corynebacterium acnes and Staphylococcus aureus) and sn-1, 3-specific lipases, which act preferentially at the $s n-1$ and $s n-3$ positions of the glycerol molecule (e.g. lipases from Rhizomucor miehei, Rhizopus oryzae, Aspergillus niger, etc.) [3]. The second group of lipases show specificity for particular fatty acids. An example is the lipase from Geotrichum candidum, which has a marked specificity for long-chain fatty acids that contain cis-9 unsaturation [4].

The microbial lipases described above have been used successfully as biocatalysts in modification of oils and fats via hydrolysis, esterification and interesterification $[5,6]$.

The lipase-catalyzed interesterification process in food industry can be used for the production of triacylglycerols with specific physical properties and it also opens possibilities for making so-called structured triacylglycerols (ST). In the literature, because of its nutritional importance, ST has received many attentions [7-11]. Reactions were performed for the production of pure ST using one or two-step enzymatic process. In terms of reaction conditions, crucial role of support for immobilization and water activity on the synthesis of ST were also reported [12-15]. Between the two enzymatic processes used for the production of ST, one step reaction, namely interesterification of a mixture of triglycerides received many attentions, because of its application for industrial purposes. The one step interesterification reaction appears very easy to carry out, but many reactions involved among various triglycerides molecules make difficult analytical analysis of products. However, species fractions of the products under substrate molar ratio have been theoretically proposed and the kinetic model of the transesterification of a mixture of mediumchain fatty acid triglycerides (MCT) and long-chain fatty acid triglycerides (LCT) was developed [16-18]. Based on this kinetic model, the rate constant of interesterification reaction was determined [18]. On the other hand, some minor compounds found in vegetable oils such as lipid hydroperoxides, phospholipids, emulsifiers, chlorophyll, carotenoids, lipid polymers, heavy metal ions and even some antioxidants had effects on activity and stability of immobilized lipases [19]. 
In the present work, activity of microbial lipases based on released fatty acid profile during hydrolysis of peanut oil using free and immobilized biocatalysts was determined. The effects of molar ratios, temperature, organic solvent on interesterification of peanut oil with tricaprylin was studied. For industrial production of ST during one step interesterification reaction, stability of immobilized lipases was investigated.

\section{Material and methods}

\section{Lipases}

Lipases used in this work were from Rhizopus sp. (RSL) (Solvay Enzymes, Hannover, Germany), Rhizomucor miehei (RML), Humicola lanuginosa (HLL), Pseudomonas fluorescens (PSL) (Biocatalyst, England), Candida rugosa (CRL) (lipase OF, Meito, Japan), Geotrichum candidum (GCL) (lipase GC, Amano, Japan), and Chromobacterium viscosum (CVL) (Asahi Chemical Industry, Japan). Two commercial lipases from Rhizomucor miehei (Lipozyme) and Candida sp. (CSL, SP 382) immobilized on an anion exchange resin, were from Novo (Bagsvaerd, Denmark). All chemicals and solvents used for analysis of the reaction products were reagent grade and purchased from common commercial supplier. Peanut oil used was purified by column chromatography.

\section{Hydrolysis of peanut oil}

Lipolysis in aqueous medium was tested with $5 \%(\mathrm{w} / \mathrm{v})$ peanut oil containing $2 \%(\mathrm{w} / \mathrm{v})$ arabic gum at $37^{\circ} \mathrm{C}, \mathrm{pH} 8$. To $20 \mathrm{~mL}$ of the emulsion, $470 \mu \mathrm{L}$ of $\mathrm{CaCl}_{2}$ solution $(22 \%(\mathrm{w} / \mathrm{v}))$ and $50 \mathrm{U}$ of crude lipase (in $50 \mathrm{mM}$ phosphate buffer at $\mathrm{pH}$ 8) or immobilized form on Celite were mixed, and the fatty acid liberated was titrated automatically with $0.1 \mathrm{~N}$ $\mathrm{NaOH}$ at constant $\mathrm{pH}$ 8.0. After $10 \mathrm{~min}$, lipolysis reaction was stopped by addition of $20 \mathrm{~mL}$ acetone/ethanol mixture $(1: 1, \mathrm{v} / \mathrm{v})$ and the products were extracted three times with $10 \mathrm{~mL}$ of ether/heptane solution $(75: 25$, $\mathrm{v} / \mathrm{v}$ ) from the emulsion. Determination of the composition of free fatty acids released during lipolysis was analysed by gas chromatography.

\section{Immobilization of lipase on Celite ${ }^{\circledR}$}

The immobilized lipases tested in this work was obtained by adsorptive binding. Before immobilization, $1.5 \mathrm{~g}$ of Celite ${ }^{\circledR} 545$ as support material was soaked with $5 \mathrm{~mL}$ of ethanol. One gram of crude microbial lipase was dissolved in $25 \mathrm{~mL}$ phosphate buffer $\mathrm{pH} 6.0,20 \mathrm{mM}$. The solution obtained was added to the wet support and stirred slowly at room temperature overnight. The immobilized enzyme preparation was collected by filtration, washed three times with $10 \mathrm{~mL}$ phosphate buffer, $\mathrm{pH}$ 6.0, $20 \mathrm{mM}$ and dried overnight under vacuum.

\section{Interesterification reaction}

Interesterification between peanut oil and tricaprylin was studied as reaction model. The reaction medium was composed of $1 \mathrm{mmoL}$ of peanut oil and $0.6 \mathrm{mmoL}$ of tricaprylin in $3 \mathrm{~mL} n$-hexane. $10 \%$ (w/w total TG) of immobilized lipases was used. In order to study the stability of immobilized lipases, ten successive transesterification reaction were carried out using the same immobilized lipase. After each batch reaction, the immobilized lipase was separated from the reaction medium, washed with chilled acetone, dried under vacuum and was used for the next reaction composed of fresh substrates.

\section{Determination of free fatty acids composition}

The extracted lipid compound from the lipolysis reaction after evaporation was dissolved in $1 \mathrm{~mL} n$-heptane in a closed test tube, and $200 \mu \mathrm{L}$ methanol containing $20 \%$ hydrochloric acid was added. The mixture obtained was shaken in a water bath at $85^{\circ} \mathrm{C}$. After $15 \mathrm{~min}$, the tube was removed from the bath and centrifuged. One $\mu \mathrm{l}$ was taken from the supernatant for GLC analysis on polar column $(25 \mathrm{~m} \times 0.53 \mathrm{~mm}$ i.d.; Macherey and Nagel, Düren, Germany). Under these conditions, only free fatty acids were converted to methyl esters [20]. Analysis was carried out with temperature programming from 150 to $210^{\circ} \mathrm{C}$ at $5^{\circ} \mathrm{C} / \mathrm{min}$, $200{ }^{\circ} \mathrm{C}$ as injection temperature, and $210^{\circ} \mathrm{C}$ as detecting temperature (flame-ionisation detector).

\section{High-performance liquid chromatography (HPLC) -Separation of ST}

The composition of the peanut oil triacylglycerols and those formed during enzymatic interesterification was characterized by HPLC using a Nucleosil $\mathrm{C}_{18}$ column $(5 \mu \mathrm{m}, 250 \times 4$ mm; Sykam, Gilching, Germany) and an evaporative light-scattering detector (Sedere, Vitry/Seine, France) at column temperature of $50{ }^{\circ} \mathrm{C}$ and a flow rate of $1.5 \mathrm{~mL} / \mathrm{min}$. Elution was performed with a linear gradient elution system of the two solvent mixtures of A (acetonitrile/isooctane (100\%) 90: 10, vol/vol) and B (acetonitrile /dichloromethane/ethanol (26\%) 40: 35: 25, vol/vol/vol) over $45 \mathrm{~min}$.

The main structured triacylglycerols identified by this analytical method are MLM and LML fractions. MLM includes MML and LMM, whereas $L M L$ includes MLL and LLM. The fatty acid M-type is indicated as mediumchain fatty acid mainly from tricaprylin and L-type as long-chain fatty acid from peanut oil.

\section{Results and discussion}

The exploitation of lipase specificity for the synthesis of various products can be tailored in aqueous media as well as in organic solvent. In this work, first, lipases screening was preferential monitored in aqueous media by $\mathrm{pH}$-stat. To determine the composition of fatty acids released during peanut oil hydrolysis catalyzed by free and immobilized lipases, a GLC-analysis of free fatty acids was performed as described in material and methods. As can be seen in figures 1 and 2, the main fatty acids released were oleic acid, linoleic acid and palmitic acid, which are the major fatty acids found in peanut oil triglycerides.

Particular long-chain fatty acids detected in peanut oil such as arachidic acid, behenic acid, which have been implicated in artherogenesis and

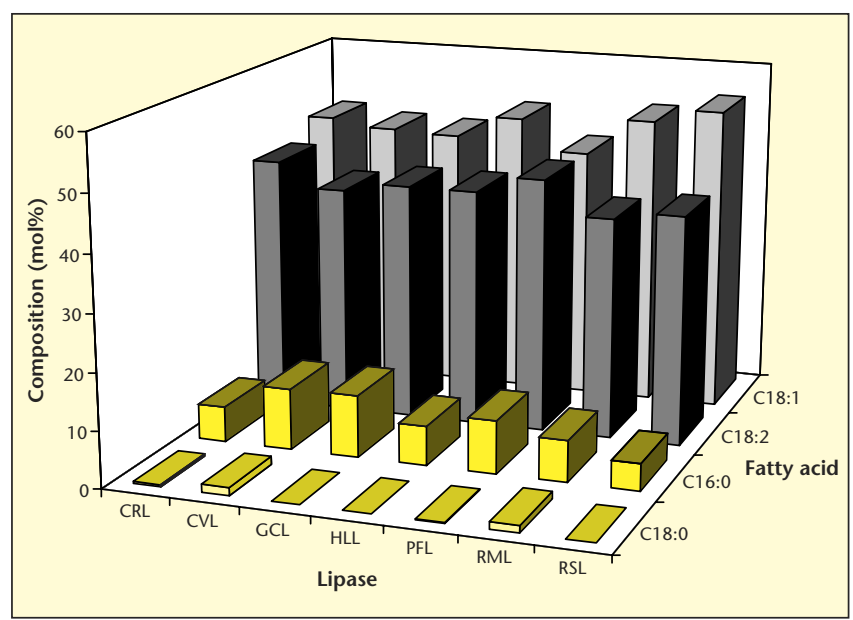

Figure 1. Composition of fatty acids released during hydrolysis of peanut oil $5 \%(\mathrm{wt} / \mathrm{v})$ after $10 \mathrm{~min}$ (at pH 8.0) using free commercial lipases. In each case, 50 Units of crude lipase were used. 


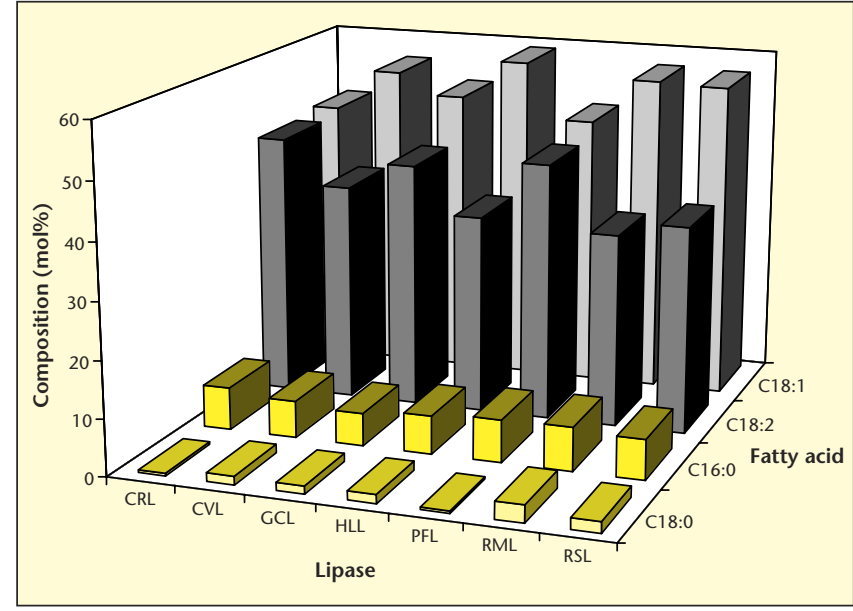

Figure 2. Composition of fatty acids released during hydrolysis of peanut oil $5 \%(\mathrm{wt} / \mathrm{v})$ after $10 \mathrm{~min}$ (at pH 8.0) using commercial lipases immobilized on Celite. In each case, 50 Units of immobilized lipases were used.

bound mainly in sn-3 position of glycerol molecule [21] were not released. As reported in the literature, triacylglycerols with long-chain fatty acids, both saturated and unsaturated were hydrolyzed at only marginally different rates using lipases from Rhizopus sp. [22, 23] and in addition the low solubility of such fatty acids in aqueous media may explain their absence in the released fatty acid fractions.

On the other hand, immobilization of lipases from Chromobacterium viscosum and Humicola lanuginosa contributes to a higher release of oleic acid than of the free enzyme (figure 2). Concerning stearic acid, only free lipase from Chromobacterium viscosum and Rhizomucor miehei were able to cleave it. Using immobilized enzymes, stearic acid was found in free fatty acids from lipolysis catalyzed by RSL, GCL and HLL. The highest stearic acid amount released (3\%) was found with immobilized lipase from Rhizomucor miehei. In such media, immobilization lipase displayed high catalytic specificity as described previously in both aqueous and organic solvents [24].

In organic solvent, immobilized lipases from Rhizomucor miehei, Candida rugosa and Chromobacterium viscosum were used for transesterification, due to their activity displayed above. Reaction standard was a transesterification of peanut oil with tricaprylin in $n$-hexane at $40^{\circ} \mathrm{C}$. To determine optimum synthesis of ST from this reaction, the effect of molar ratio of substrate on the production of ST was investigated using immobilized RML. As can be seen in figure 3, the best molar ratio found was between 0.7 and 0.8 (mole tricaprylin to mole peanut oil). From molar ratio 0.9 to 1.5 , the amount of MLM fraction increased, followed by an increase in the remaining concentration of tricaprylin (data not shown).

Interesterification reaction involves several steps and fatty acids from natural oil as well as from medium-chain triglycerides such as tricaprylin must be released before subsequent esterification to ST can occur. The increase of remaining concentration of tricaprylin mentioned above may be due to the different specificity showed among natural oil triglycerides and tricaprylin by immobilized lipases.

Organic solvents are used in most of reaction catalyzed by immobilized lipases, because enzyme shows high stability in some organic solvents. Furthermore, organic solvents improve the solubility of substrates and thus, increase the initial rate of the reaction. To investigate the effect of organic solvent on the synthesis of ST, the three immobilized listed above were used as catalysts in various organic solvents. The results are indicated in table 1. In all organic solvents tested, the concentration of MLM was lower than that for LML (table 1). Except for RML, in petroleum ether and for all immobilized lipases in cyclohexane, the concentration of ST

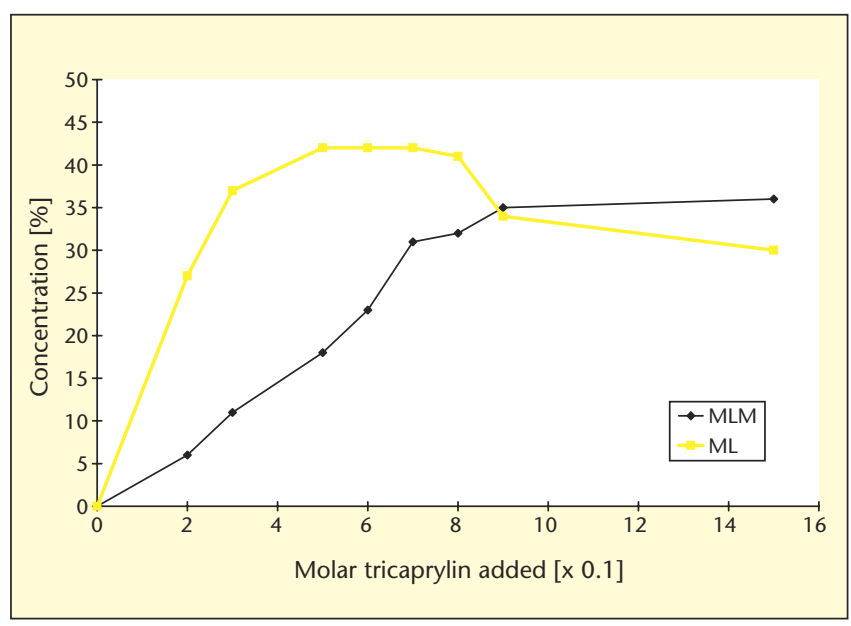

Figure 3. Effect of tricaprylin: peanut oil molar ratio on the synthesis of structured triglycerides (ST) using immobilized RML in $n$-hexane at $40^{\circ} \mathrm{C}$.

was high in most of cases. On the other hand, a solvent free system for the production of ST also led to a high yield and in some cases is quite similar to that found in organic solvents (table 1). The yield found here was lower than that obtained from the transesterification of olive oil with trimyristin (90\%) and tristearin with tricaprin $(84.7 \%)[25,26]$. Because of the high solubility of medium-chain fatty acid such as caprylic acid in water, their concentration is reduced at the interface and thereby reduces their exchange in triglycerides [27]. This may explain the low yield of ST obtained in the present work.

For industrial purposes, repeated interesterification using the same immobilized biocatalyst is of great importance. To investigate stability of commercial immobilized RML and CRL, nine batches interesterification of peanut oil and tricaprylin in a solvent free system were studied. For this study, the immobilized lipases were isolated from reaction products as described in material and methods. figures 4 and 5 show the experimental results of produced structured triglycerides of MLM and LML types during reused immobilized lipases

The determination of relative concentration of each fraction was based on the amount of the structured triacylglycerols produced at the first use of biocatalysts.

As can be seen in these figures, after 7 repeated uses, no significant loss in terms of amount of structured produced triglycerides was observed with RML, whereas with CRL, decrease in the amount of synthesized triglycerides appeared after batch 5 and was more pronounced with triglyceride of the LML-type.

\section{Conclusion}

Most of informations known about enzymes have been learned from studies in aqueous solutions. In this medium, determination of fatty acids released during lipolysis of peanut oil using microbial free and immobilized lipases was performed through $\mathrm{pH}$-stat. Among microbial lipases tested in this work, lipase specificity was altered through immobilization in emulsion media, namely with Chromobacterium viscosum, Geotrichum candidum, Humicola lanuginosa, Rhizomucor miehei and Rhizopus sp. lipases.

Although aqueous media is a solvent of choice, non-aqueous solvents for enzymatic reactions have been introduced and are of great biotechnological interest, namely for the synthesis of ST. In the present work, the best concentration of ST (79\%) from the transesterification of peanut oil with tricaprylin was found in n-hexane with RML. The concentration of 
Table 1. Effect of reaction system on the synthesis of structured triacylglycerols from interesterification of peanut oil and tricaprylin in molar ratio 0.7 (tricaprylin to peanut oil, $\mathrm{mol} / \mathrm{mol}$ ) after $24 \mathrm{~h}$.

\begin{tabular}{|c|c|c|c|c|c|}
\hline \multirow[t]{2}{*}{ Lipase } & \multirow[t]{2}{*}{ Reaction system } & \multirow{2}{*}{$\begin{array}{c}\text { Temperature } \\
{\left[{ }^{\circ} \mathrm{C}\right]}\end{array}$} & \multicolumn{2}{|c|}{ ST (wt\%) } & \multirow{2}{*}{$\begin{array}{c}\text { Total ST } \\
\text { (wt } \%)\end{array}$} \\
\hline & & & MLM & LML & \\
\hline \multirow[t]{7}{*}{ CSL } & without solvent & 60 & 28 & 39 & 67 \\
\hline & $n$-hexane & 50 & 31 & 37 & 68 \\
\hline & isohexane & 50 & 33 & 39 & 72 \\
\hline & cyclohexane & 50 & 31 & 29 & 60 \\
\hline & heptane & 50 & 27 & 40 & 67 \\
\hline & isooctane & 50 & 31 & 38 & 69 \\
\hline & petroleum ether & 50 & 30 & 40 & 70 \\
\hline \multirow[t]{7}{*}{ CVL } & without solvent & 60 & 33 & 42 & 75 \\
\hline & $n$-hexane & 50 & 32 & 40 & 72 \\
\hline & isohexane & 50 & 33 & 43 & 76 \\
\hline & cyclohexane & 50 & 24 & 35 & 59 \\
\hline & heptane & 50 & 31 & 42 & 73 \\
\hline & isooctane & 50 & 31 & 42 & 73 \\
\hline & petroleum ether & 50 & 33 & 41 & 74 \\
\hline \multirow[t]{7}{*}{ RML } & without solvent & 60 & 31 & 42 & 73 \\
\hline & $n$-hexane & 50 & 35 & 44 & 79 \\
\hline & isohexane & 50 & 34 & 42 & 76 \\
\hline & cyclohexane & 50 & 30 & 39 & 69 \\
\hline & heptane & 50 & 31 & 43 & 74 \\
\hline & isooctane & 50 & 31 & 42 & 73 \\
\hline & petroleum ether & 50 & 28 & 32 & 60 \\
\hline
\end{tabular}

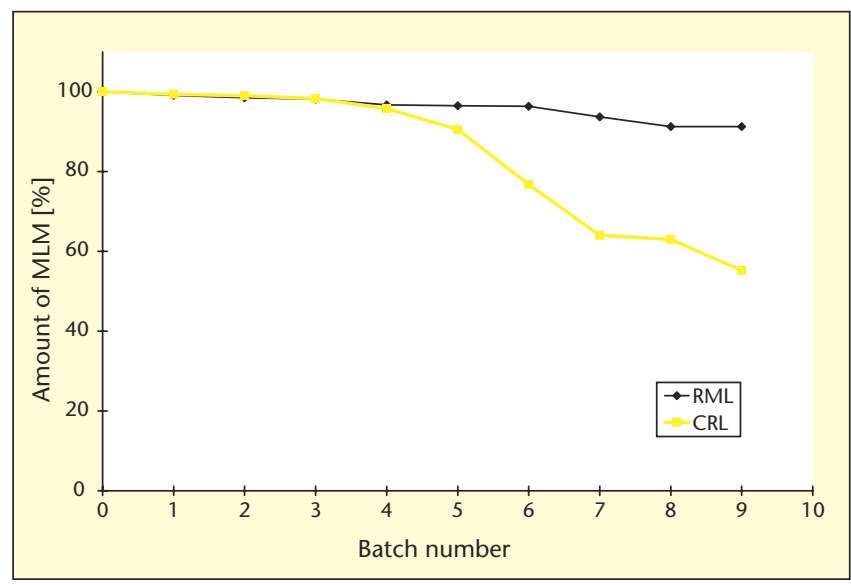

Figure 4. Effect of reused immobilized RML and CRL on the synthesis of MLM fractions from a mixture of tricaprylin and peanut oil in a solvent free system at $60^{\circ} \mathrm{C}$.

ST obtained in a solvent free system after $24 \mathrm{~h}(>65 \%)$ is quite similar to that found in organic solvents. In such medium, RML maintained its activity during nine successive batch transesterification of peanut oil with tricaprylin. For industry point of view, the developed synthesis transesterification can find application for the modification of coating or nutrional properties of fats and oils.

\section{REFERENCES}

1. MARANGONI AG, ROUSSEAU D. Engineering triacylglycerols: the role of interesterification. Trends Food Sci Technol 1995; 6: 329-35.

2. ROUSSEAU D, MARANGONI AG. Chemical interesterification. In: Akoh CC, Min DB, eds. Food Lipids. New York: Marcel Dekker Inc, 1998: 251-81.

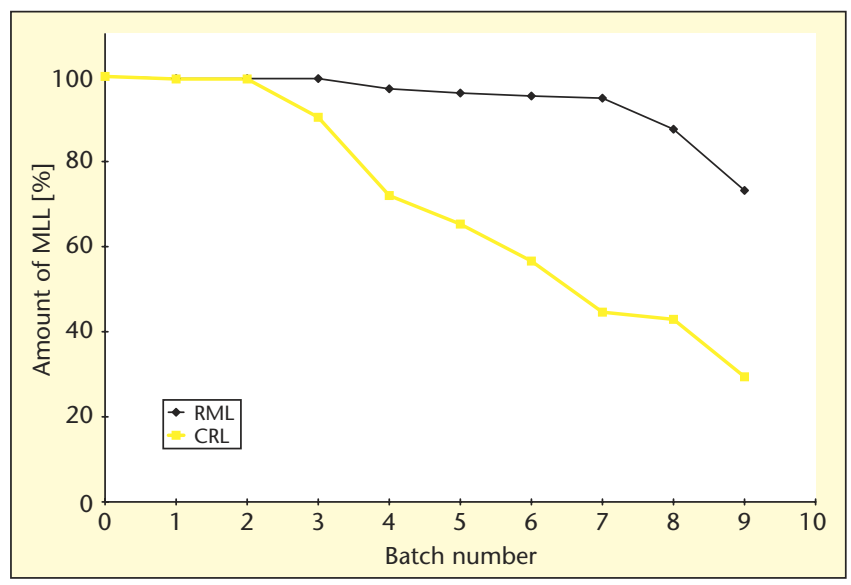

Figure 5. Effect of reused immobilized RML and CRL on the synthesis of $L M L$ fractions from a mixture of tricaprylin and peanut oil in a solvent free system at $60^{\circ} \mathrm{C}$.

3. CHANDLER JC. Determining the regioselectivity of immobilized lipases in triacylglycerol acidolysis reactions. J Am Oil Chem Soc 2001; 78: 737-42.

4. JENSEN RG. Characteristics of the lipase from the mold Geotrichum candidum: a review. Lipids 1974; 6: 149-57.

5. MACRAE AR. Lipase-catalyzed interesterification of oils and fats. / Am Oil Chem Soc 1983; 60: 243-6.

6. GANDHI NN. Applications of lipase. / Am Oil Chem Soc 1997; 74: 621-34.

7. SOUMANOU MM, BORNSCHEUER UT, SCHMID RD. Two-step enzymatic reaction for the synthesis of pure structured triacylglycerides. J Am Oil Chem Soc 1998; 75: 703-10.

8. MIURA S, OGAWA A, KONISHI H. A rapid method for enzymatic and purification of the structured triacylglycerol 1,3-Dilauroyl-2-oleoyl-glycerol. / Am Oil Chem Soc 1999; 76: 927-31. 
9. IWASAKI Y, YAMANE T. Enzymatic synthesis of structured lipids. J Mol Catal, B Enzym 2000; 10: 129-40.

10. BORNSCHEUER UT. In: Lipase-catalyzed synthesis of structured triacylglycerols. Lipid Technol Newsletter, 2001: 104-7.

11. BORNSCHEUER UT, ADAMCZAKM, SOUMANOU MM. Lipase-catalyzed synthesis of modified lipids. In: Gunstone FD, Barnes PJ, eds. Lipids as Constituents of Functional Foods. England: Bridgwater, 2003: 149-82; and Associates.

12. GOLDBERG M, THOMAS D, LEGOY MD. Water activity as a key parameter of synthesis reactions: the example of lipases in biphasic (liquid/solid) media. Enzyme Microb Technol 1990; 17: 976-81.

13. HALLING PJ. Thermodynamic predictions for biocatalysis in nonconventional media: theory, tests, and recommendations for experimental design and analysis. Enzyme Microb Technol 1994; 16: 178-206.

14. SOUMANOU MM, BORNSCHEUER UT, SCHMID U, SCHMID RD. Crutial role of support and water activity on the lipase-catalyzed synthesis of structured triglycerides. Biocatal Biotransf 1999; 16: 443-59.

15. HAN J], YAMANE T. Enhancement of both reaction yield and rate of synthesis of structured triacylglycerol containing eicosapentaenoic acid under vacuum with water activity control. Lipds 1999; 34: 989-95.

16. BASHEER S, SNAPE JB, MOGI K, NAKAJIMA M. Tranesterification kinetics of triglycerides for a modified lipase in $n$-hexane. J Am Oil Chem Soc 1995; 72: 231-7.

17. XUX. Modification of oils and fats by lipase-catalyzed interesterification: aspects of process engineering. In: Bornscheuer UT, ed. Enzymes in Lipid Modification. Weinheim: Wiley-VCH Verlag GmbH, 2000: 190-215.

18. MOGI K, NAKAJIMA M, MUKATABA S. Transesterification reaction between medium- and long-chain acid triglycerides using surfactant-modified lipase. Biotechnol Bioeng 2000; 67: 513-9.
19. XU X, HOY CE, ADLER-NISSEN J. Effects of lipid-borne compounds on the activity and stability of lipase in microaqueous systems for lipase-catalyzed reaction. In: Ballesteros A, Plou PJ, Iborra JL, Halling P, eds. Stability and Stabilization of Biocatalysts. Amsterdam: Elsevier Science, 1998: 441-6.

20. BADINCS HT, DE JONG C. Glass capillary gas chromatography of fatty acid methyl esters. A study of conditions for the quantitative analysis of short- and long-chain fatty acids in lipids. J Chromatogr 1983; 279: 493-506.

21. SRIDHAR R, LAKSHMINARAYANA G, KAIMAL TNB. Modification of selected edible vegetable oils to high oleic oils by lipase-catalyzed ester interchange. J Agric Food Chem 1991; 39: 2069-71.

22. HUGE-JENSEN B, GALLUZZO DR, JENSEN RG. Studies on free and immobilized lipases from Mucor miehei. / Am Oil Chem 1988; 65: 905-10.

23. ATOMI H, BORNSCHEUER U, SOUMANOU MM, BEER HD, WOHLFAHRT G, SCHMID RD. Microbial lipases-from screening to design. In: Barnes PJ, ed. Oils-Fats-Lipids, 21st World Congress Int Soc Fat Res. England: Bridgwater, 1995: 49-50; and Associates, Vol. 1.

24. JENSEN BF, EIGTVED P. Safety aspects of microbial enzyme technology, exemplified by the safety assessment of an immobilized lipase preparation

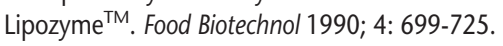

25. JUNG HJ, BAUER W. Determination of process parameters and modelling of lipase catalyzed transesterification in a fixed bed reactor. Chem Eng Technol 1992; 15: 341-8.

26. AKOH CC, YEE LN. Enzymatic synthesis of position-specific low-calorie structured lipids. I Am Oil Chem Soc 1997; 74: 1409-13.

27. KIMURA M, HASEGAWA K, TAKAMURA H, MATOBA T. Preparation of triacylglycerols molecular species by interesterifcation using endocellular lipase in $n$-hexane. Agric Biol Chem 1991; 55: 3039-43. 